\title{
Single VDGA-Based Dual-Mode Multifunction Biquadratic Filter and Quadrature Sinusoidal Oscillator
}

\author{
Worapong Tangsrirat ${ }^{1}$, Tattaya Pukkalanun ${ }^{1}$, Orapin Channumsin ${ }^{2 *}$
}

${ }^{1}$ Faculty of Engineering, King Mongkut's Institute of Technology Ladkrabang (KMITL), Bangkok 10520, Thailand

${ }^{2}$ Faculty of Engineering, Rajamangala University of Technology Isan, Khonkaen Campus, Khonkaen 4000, Thailand

\begin{abstract}
This article relates to the realization of voltage-mode and/or current-mode multifunction biquadratic filter and quadrature oscillator circuits each using one voltage differencing gain amplifier (VDGA), two resistors and two grounded capacitors. The proposed dual-mode filter having one output and three inputs can provide the three standard biquadratic transfer functions with both voltage and current output filter responses simultaneously. It also has the independent tuning of the angular resonance frequency and the quality factor. With a slight modification of the proposed filter, a new dual-mode quadrature sinusoidal oscillator can be obtained. The proposed quadrature oscillator provides orthogonal resistive/electronic control of both oscillation condition and oscillation frequency. Non-ideal and parasitic conditions are also examined and their effects on the circuit performance are discussed. To confirm the theory, several computer simulation results with PSPICE program are given.
\end{abstract}

Keywords: Voltage Differencing Gain Amplifier (VDGA); biquadratic filter; quadrature oscillator; dual-mode operation; voltage-mode circuit; current-mode circuit

\section{Enojen multifunkcijski bi-kvadratičen filter na osnovi VDGA in sinusni kvadrantni oscilator}

\begin{abstract}
Izvleček: Članek opisuje multifunkcijski bi-kvadratičen filter v napetostnem in/ali tokovnem načinu ter kvadrantni oscilator. Oba sta zasnovana na osnovi VDGA ojačevalnik, dveh uporov in dveh ozemljenih kondenzatorjev. Predlagan filter ima en izhod in tri vhode, kar omogoča uporabo treh standardnih bikvadratičnih funkcij sočasno na napetostnem in tokovnem izhodu. Omogoča tudi neodvisno nastavljanje kotne resonančne frekvence in faktorja kvalitete. Z majhnimi spremembami lahko dobimo sinusni oscilator. Raziskani so tudi neidealni in parazitni pogoji in njihov vpliv na učinkovitost vezja. Teorija je bila preverjena v PSPICE simulacijskem okolju.
\end{abstract}

Ključne besede: (VDGA); bikvadratičen filter; kvadrantni oscillator; napetostni način; tokovni način

*Corresponding Author's e-mail: o.channumsin.rmuti@gmail.com

\section{Introduction}

Multifunction filters, which can simultaneously realize low-pass (LP), band-pass (BP) and high-pass (HP) filter responses with the same configuration, are fundamental circuit elements widely used in the design of several electronic systems, such as phase-locked loop frequency modulators, crossover networks, stereo demodulators, etc.[1]-[2]. For decades, multifunction biquadratic filters have been designed by using numerous modern electronic active elements, such as second-generation current conveyor (CCII) [1], [5]-[9], differential voltage current conveyor (DVCC) [2]-[3], [10]-[11], differential difference current conveyor (DDCC) [4], differential voltage current conveyor transconductance amplifier (DVCCTA) [12], universal voltage conveyor (UVC) [13], unity gain cells [14]-[15], current-controlled current conveyor (CCCII) [16], voltage differencing gain amplifier (VDGA) [19], voltage differencing transconductance amplifier (VDTA) 
[20-23]. Considering the number of input and output terminals, the previously designed configurations in literature can be classified as single-input multi-output (SIMO) [1], [3-7], [11-15], [18], [19], [22-23], multi-input single-output (MISO) [8], [10], [21] and multi-input multioutput (MIMO) [9], [16-17] filter topologies. If the type of signal processing is considered, these filters can further be classified as voltage-mode [3-7], [10-13], [16], [20], current-mode [1-2], [8-9], [14], [17-18], [21], and dualmode [15], [19], [22-23] filter topologies. However, this finding focuses on the design of the dual-mode SIMO multifunction biquad filter with both voltage and current output responses using only a single active element. The topology in the literature [15] needs to employ four voltage followers, four dual-output current followers, seven resistors, and two grounded capacitors. In [19], the single -input three-output dual-mode multifunction filter was developed by using two VDGAs and three capacitors. However, this configuration does not have the feature of independent control of its natural angular frequency $\left(\omega_{0}\right)$ and quality factor $(Q)$. Separate studies in [22-23] introduced SIMO dual-mode biquad filters combining a single VDTA, one grounded resistor, and three capacitors. Both the circuits still require a floating capacitor and also perform only a biquadratic filter.

In the design of electronic communication and control systems, sinusoidal quadrature oscillators (QOs) which can provide two periodic waveforms with a phase difference of $90^{\circ}$ are necessarily needed. Application tasks of QO are, for example, in quadrature mixers for mixing the analog signal outputs, in phase sensitive detection systems for generating reference signals, and in measurement systems for testing electronic device and circuit characteristics. Up to now, several variable frequency quadrature oscillator circuits have been built employing various types of active elements, such as operational amplifier [24], CCII [25-26], DDCC [27], four terminal floating nullor (FTFN) [28-30], current feedback operational amplifier (CFOA) [31-33], current differencing buffered amplifier (CDBA) [34-35], current differencing transconductance amplifier (CDTA) [3638], VDTA [39], and voltage differencing buffered amplifier (VDBA) [40]. Note that the above mentioned QO circuits are useful in either voltage [24-27], [31-32], [3435], [39-40] or current-mode [28-30], [33], [36-38] applications. Some QO configurations were developed in [41-49], where the voltage and current quadrature outputs are generated simultaneously. Several dual-mode QOs make use of one or more active elements [42-44], [47], [49]. Although another set of compact QO realizations using a single active element were proposed in [46], [48], they do not permit non-interactive control of the condition of oscillation (CO) and the frequency of oscillation $\left(\omega_{\text {osc }}\right)$. Besides, the possible realization of the dual-mode multifunction biquad filter is not available with any of the previously mentioned $\mathrm{QO}$ realizations.

This contribution led us to the design of the dual-mode multifunction biquad filter and sinusoidal quadrature oscillator which can provide both voltage and current output signals simultaneously. Each of the proposed configurations includes only a single voltage differencing gain amplifier (VDGA) [50], two resistors, and two grounded capacitors. The proposed dual-mode multifunction biquad configuration can orthogonally control of $\omega_{o}$ and $Q$. With a slight modification of the proposed biquad, a compact dual-mode QO circuit with non-interactive adjustment of $\mathrm{CO}$ and $\omega_{\text {osc }}$ is also obtained. Non-ideal characteristics parasitic element effects on the behavior of the proposed circuits are considered. The working of the circuits is evaluated by simulation results.

\section{VDGA Description}

The VDGA device is a versatile six-terminal active building block, which is recently introduced in [50]. As a consequence, a variety of VDGA-based analog circuit applications have been developed in technical literature, such as active filters [50]-[51], quadrature sinusoidal oscillators [52]-[53], and capacitance multiplier circuit [54]. Its schematic symbol is shown in Fig.1, where $p$ and $n$ are high-impedance voltage input ports, $\mathrm{z}+, \mathrm{z}-$ and $\mathrm{x}$ are high-impedance current output ports, and $w$ is low-impedance voltage output port. The ideal property of the VDGA device can be characterized as in the following matrix equation:

$$
\left[\begin{array}{c}
i_{z+} \\
i_{z-} \\
i_{x} \\
v_{w}
\end{array}\right]=\left[\begin{array}{cccc}
g_{m A} & -g_{m A} & 0 & 0 \\
-g_{m A} & g_{m A} & 0 & 0 \\
0 & 0 & g_{m B} & 0 \\
0 & 0 & \beta & 0
\end{array}\right]\left[\begin{array}{c}
v_{p} \\
v_{n} \\
v_{z+} \\
v_{x}
\end{array}\right],
$$

where $g_{m A}$ and $g_{m B}$ are the transconductance gains, and $\beta$ is the transfer voltage gain of the VDGA.

Fig. 2 shows a CMOS implementation of the VDGA used in this work, and it is derived from the one in [50]. According to [55], it can be realized from Fig.2 that each transconductance $g_{m k}(k=A, B, C)$ of the VDGA can be determined by:

$$
g_{m k} \cong\left(\frac{g_{1 k} g_{2 k}}{g_{1 k}+g_{2 k}}\right)+\left(\frac{g_{3 k} g_{4 k}}{g_{3 k}+g_{4 k}}\right),
$$

where

$$
g_{i k}=\sqrt{K I_{B k}},
$$




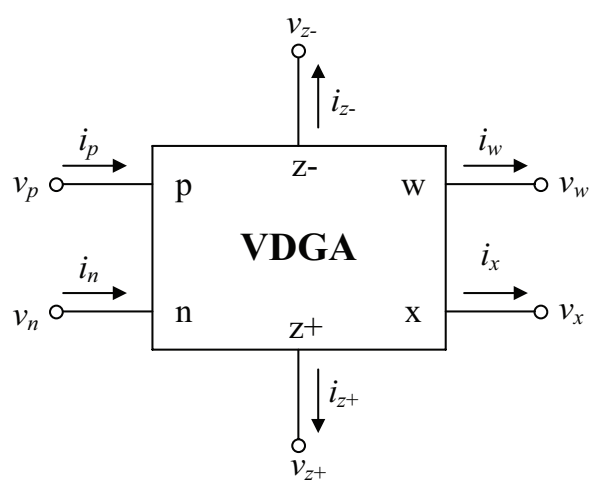

Figure 1: VDGA schematic representation.

for $i=1,2,3,4$ and the parameter $K$ is the transconductance of the transistor $M_{i k}$. From equations (2) and (3), the value of $g_{m k}$ can be scaled electronically, since each transconductance $g_{i k}$ is proportional to the square root of the bias current $I_{B k}$. Furthermore, a pair of transconductors $M_{1 B}-M_{9 B}$ and $M_{1 C}-M_{9 C}$ performs a current-controlled voltage amplifier with the voltage transfer gain $\mathrm{b}=v_{w} / v_{z+}=g_{m B} / g_{m c}$.

\section{Proposed dual-mode multifunction biquadratic filter}

The proposed dual-mode multifunction biquadratic filter topology is shown in Fig.3. It essentially comprises a single VDGA, two grounded capacitors and two resistors (one of them is grounded). A straightforward analysis with $i_{i n}=0$ provides the three voltage transfer functions as follows:

$$
\begin{aligned}
& \frac{V_{o 1}(s)}{V_{\text {in }}(s)}=g_{m A} R_{1}\left[\frac{\frac{s}{R_{1} C_{1}}}{D(s)}\right], \\
& \frac{V_{o 2}(s)}{V_{i n}(s)}=\left[\frac{\frac{g_{m A} g_{m B}}{C_{1} C_{2}}}{D(s)}\right],
\end{aligned}
$$

and

$$
\frac{V_{o 3}(s)}{V_{i n}(s)}=-\left(g_{m A} R_{2}\right)\left[\frac{s^{2}}{D(s)}\right],
$$

where

$$
D(s)=s^{2}+\left(\frac{s}{R_{1} C_{1}}\right)+\left(\frac{g_{m A} g_{m B}}{C_{1} C_{2}}\right) .
$$

Therefore, the proposed circuit of Fig. 3 provides a noninverting $\mathrm{BP}$, a non-inverting $\mathrm{LP}$ and an inverting $\mathrm{HP}$ filter voltage response at the output voltages $v_{o 1^{\prime}} v_{o 2^{\prime}}$ and $v_{o 3^{\prime}}$ respectively. Equations (4)-(7) suggest that the characteristics $\omega_{0}$ and $Q$ of the filter are obtained as :

$$
\omega_{o}=2 \pi f_{o}=\sqrt{\frac{g_{m A} g_{m B}}{C_{1} C_{2}}},
$$

and

$$
Q=R_{1} \sqrt{\frac{g_{m A} g_{m B} C_{1}}{C_{2}}} .
$$

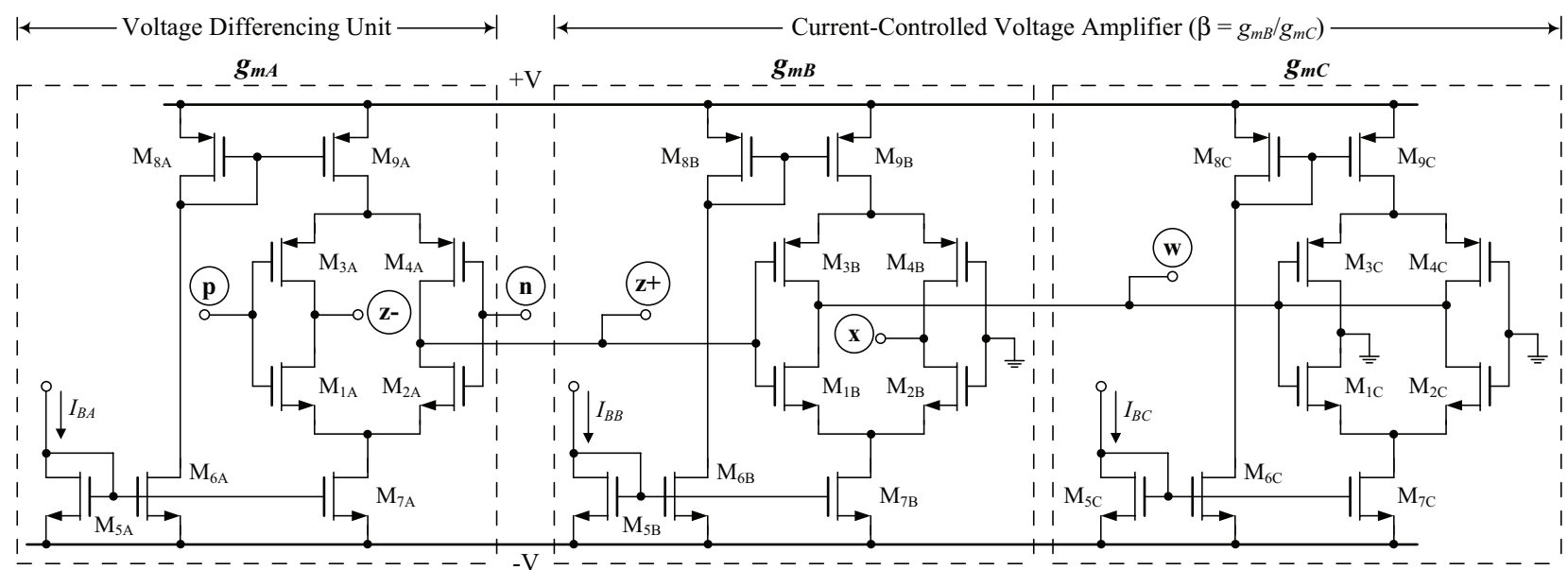

Figure 2: Internal circuit configuration of the CMOS VDGA. 
It is important to note that the parameter $\omega_{0}$ is now tunable electronically by adjusting $g_{m A}$ and/or $g_{m B^{\prime}}$ while the value of the $Q$-factor is adjustable through the value of $R_{1}$ without affecting $\omega_{0}$. In other words, the parameters $\omega_{o}$ and $Q$-factor of the filter are orthogonally controllable.

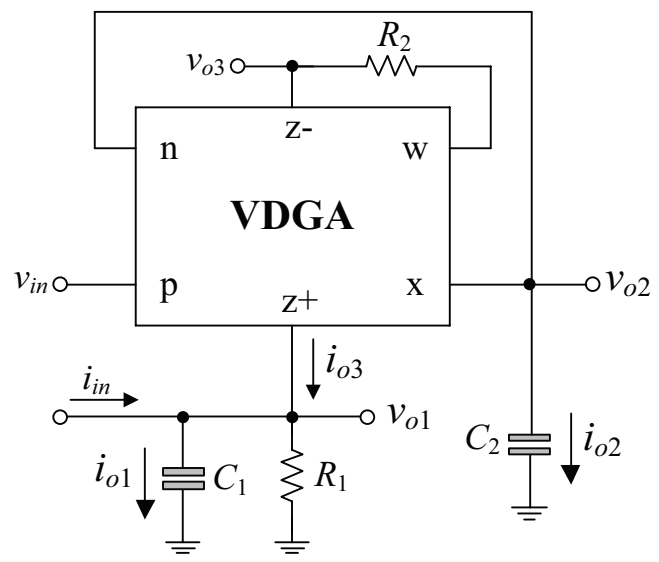

Figure 3: Proposed dual-mode multifunction biquadratic filter.

Considering again the proposed dual-mode frequency filter given in Fig.3, its routine algebraic analysis with $v_{\text {in }}=0$ also reveals the three following current transfer functions:

$$
\begin{aligned}
& \frac{I_{o 1}(s)}{I_{\text {in }}(s)}=\left[\frac{s^{2}}{D(s)}\right], \\
& \frac{I_{o 2}(s)}{I_{i n}(s)}=\left(g_{m B} R_{1}\right)\left[\frac{\frac{s}{R_{1} C_{1}}}{D(s)}\right],
\end{aligned}
$$

and

$$
\frac{I_{o 3}(s)}{I_{i n}(s)}=-\left[\frac{\frac{g_{m A} g_{m B}}{C_{1} C_{2}}}{D(s)}\right],(
$$

where the denominator $D(s)$ is the same as in equation (7). It is clear from equations (10)-(12) that, by the same structure, current-mode $\mathrm{HP}, \mathrm{BP}$, and inverting LP responses are simultaneously obtained at $i_{01^{\prime}}, i_{{ }^{2}{ }^{\prime}}$ and $i_{o 3^{\prime}}$ respectively. For this version, the $\omega_{0}$ and the $Q$-factor are the same as those given in equations (8) and (9).

\section{Proposed dual-mode quadrature sinusoidal oscillator}

From Fig.3, it is further noted that the dual-mode quadrature sinusoidal oscillator is obtainable by setting $i_{\text {in }}=$ 0 , and connecting the $p$-terminal to the $w$-terminal of the VDGA. The resulting QO circuit is depicted in Fig.4, and its characteristic equation is found as:

$$
s^{2}+\frac{s}{C_{1}}\left(\frac{1}{R_{1}}-g_{m A} \beta\right)+\left(\frac{g_{m A} g_{m B}}{C_{1} C_{2}}\right)=0 .
$$

From the above equation, the $\mathrm{CO}$ and $\omega_{\text {osc }}$ of the realized QO are respectively given by:

$$
\frac{1}{R_{1}}=g_{m A} \beta
$$

and

$$
\omega_{o s c}=2 \pi f_{o s c}=\sqrt{\frac{g_{m A} g_{m B}}{C_{1} C_{2}}} .
$$

It is clear from equations (14) and (15) that the CO of the oscillator can be varied independently of $\omega_{\text {osc }}$ by $R_{1}$. This QO provides two voltage outputs and two current outputs, which relate as follows:

$$
V_{o 1}=\left(\frac{\omega_{o s c} C_{2}}{g_{m B}}\right) e^{j 90^{\circ}} V_{o 2},
$$

and

$$
I_{o 1}=\left(\frac{\omega_{o s c} C_{1}}{g_{m B}}\right) e^{j 90^{\circ}} I_{o 2} .
$$

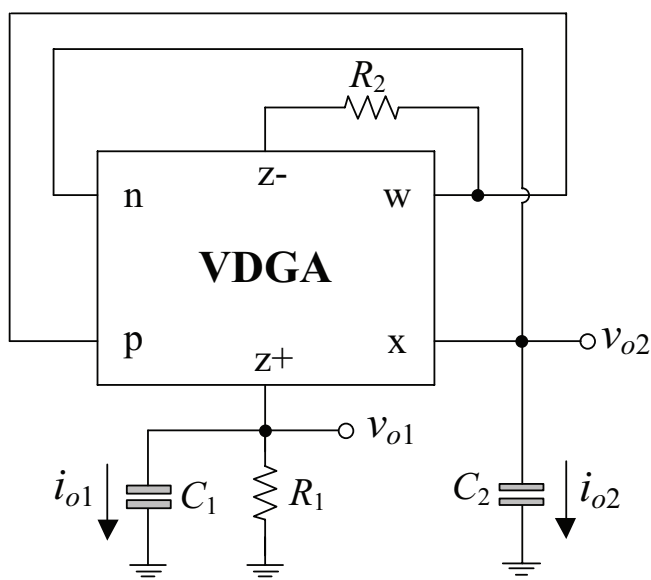

Figure 4: Proposed dual-mode quadrature sinusoidal oscillator. 
Equations (16) and (17) show that the two voltage and current outputs are each other shifted in phase by $90^{\circ}$, thereby exhibiting quadrature property to the proposed QO circuit. Moreover, the proposed oscillator also offers versatility by simultaneously providing both quadrature voltage as well as current outputs.

\section{Effect of VDGA Non-idealities}

\subsection{Effect of transfer errors}

Taking into consideration the VDGA non-idealities, the characteristic of the practical VDGA can be written as:

$$
\left[\begin{array}{c}
i_{z+} \\
i_{z-} \\
i_{x} \\
v_{w}
\end{array}\right]=\left[\begin{array}{cccc}
\alpha_{A} g_{m A} & -\alpha_{A} g_{m A} & 0 & 0 \\
-\alpha_{A} g_{m A} & \alpha_{A} g_{m A} & 0 & 0 \\
0 & 0 & \alpha_{B} g_{m B} & 0 \\
0 & 0 & \delta \beta & 0
\end{array}\right]\left[\begin{array}{c}
v_{p} \\
v_{n} \\
v_{z+} \\
v_{x}
\end{array}\right] .
$$

In above expression, $a_{k}\left(a_{k}=1-\varepsilon_{\alpha}\right)$ is the transconductance inaccuracy parameter and $\delta\left(\delta=1-\varepsilon_{\delta}\right)$ is the nonideal voltage transfer gain of the VDGA. These unwanted parameters alter from unity by the transfer errors $\varepsilon_{\alpha}$ $\left(\left|\varepsilon_{a}\right|<<1\right)$ and $\varepsilon_{\delta}\left(\left|\varepsilon_{\delta}\right|<<1\right)$, respectively.

The proposed dual-mode multifunction biquadratic filter of Fig. 3 is re-analyzed using the non-ideal performance relation (18) of VDGA, and the non-ideal $\omega_{o}$ and $Q$ become as follows:

$$
\omega_{o}=2 \pi f_{o}=\sqrt{\frac{\alpha_{A} \alpha_{B} g_{m A} g_{m B}}{C_{1} C_{2}}},
$$

and

$$
Q=R_{1} \sqrt{\frac{\alpha_{A} \alpha_{B} g_{m A} g_{m B} C_{1}}{C_{2}}} .
$$

Equations (19) and (20) indicate that the transfer errors directly affect the parameters $\omega_{o}$ and $Q$ of the filter. However, since $a_{A}$ and $a_{B}$ are typically close to unity, these small deviations can be compensated by slightly re-adjusting the values of $g_{m A}$ and $g_{m B}$ via the bias currents $I_{B A}$ and $I_{B B^{\prime}}$, respectively.

Similarly, in the non-ideal case, the characteristic equation of the proposed dual-mode QO circuit in Fig.4 can be found as:

$$
s^{2}+\frac{s}{C_{1}}\left(\frac{1}{R_{1}}-\alpha_{A} \delta g_{m A} \beta\right)+\left(\frac{\alpha_{A} \alpha_{B} g_{m A} g_{m B}}{C_{1} C_{2}}\right)=0,
$$

where the parameters $\mathrm{CO}$ and $\omega_{\text {osc }}$ of the oscillator for this case are modified as:

$$
\frac{1}{R_{1}}=\alpha_{A} \delta g_{m A} \beta
$$

and

$$
\omega_{o s c}=\sqrt{\frac{\alpha_{A} \alpha_{B} g_{m A} g_{m B}}{C_{1} C_{2}}} .
$$

The $\mathrm{CO}$ and $\omega_{\text {osc }}$ of the oscillator are deviated from the ideal case by the non-ideal transfer gains. In the same manner, because the voltage transfer gain $\beta$ is proportional to $g_{m B} / g_{m C^{\prime}}$ the transconductance $g_{m c}$ is adjustable to minimize the influence of $a_{A}$ and $\delta$ on the CO. Also, note from (23) that the slight $\omega_{\text {osc }}$ deviation can be overcome by re-tuning $g_{m A}$ and $g_{m B}$.

\subsection{Effect of parasitic elements}

In practice, a parasitic problem should be taken into count to determine the effects of the VDGA parasitic impedances on the proposed circuits. Fig.5 displays a sophisticated equivalent model behavior that represents the practical VDGA. In Fig.5, the dashed line encircles the practical VDGA, while the continuous line denotes the ideal VDGA with various parasitic elements at its terminals. As can be seen, there are parasitic parallel resistances and capacitances from terminals $\mathrm{p}, \mathrm{n}$, $z+$ and $z$ - to ground $\left[\left(R_{p} / / C_{p}\right),\left(R_{n} / / C_{n}\right),\left(R_{z+} / / C_{z+}\right)\right.$ and $R_{z-} / /$ $\left.\left.C_{z}\right)\right]$, and a parasitic serial resistance $\left(R_{w}\right)$ at the terminal $w$. Therefore, by applying the practical model of the VDGA to the proposed dual-mode multifunction filter in Fig. 3 and assuming the condition $R_{2} \gg R_{w^{\prime}}$ the modified $\omega_{\circ}$ and $Q$ can be expressed as:

$$
\omega_{o}=\sqrt{\frac{g_{m A} g_{m B}+\left(\frac{1}{R_{1}^{\prime} R_{x}^{\prime}}\right)}{C_{1}^{\prime} C_{2}^{\prime}}},
$$

and

$$
Q=\left[\frac{R_{1}^{\prime} R_{x}^{\prime}}{R_{1}^{\prime} C_{1}^{\prime}+R_{x}^{\prime} C_{2}^{\prime}}\right] \sqrt{\left[g_{m A} g_{m B}+\left(\frac{1}{R_{1}^{\prime} R_{x}^{\prime}}\right)\right] C_{1}^{\prime} C_{2}^{\prime} .}
$$

where $R_{1}^{\prime}=R_{1} / / R_{z t^{\prime}} R_{x}^{\prime}=R_{x} / / R_{n^{\prime}} C_{1}=C_{1}+C_{z+}$ and $C_{2}=C_{2}$ $+C_{x}+C_{n}$.

In a similar way, accounting for the VDGA parasitic elements given in Fig.5, the $\mathrm{CO}$ and $\omega_{\text {osc }}$ of the proposed dual-mode sinusoidal QO in Fig.4 can be derived as:

$$
\left(\frac{1}{R_{1}^{\prime}}+\frac{C_{1}^{\prime}}{R_{x}^{\prime} C_{2}^{\prime}}\right)=\beta g_{m A}
$$


and

$$
\omega_{o s c}=\sqrt{\frac{g_{m A} g_{m B}+\left(\frac{1}{R_{1}^{\prime} R_{x}^{\prime}}\right)}{C_{1}^{\prime} C_{2}^{\prime}}} .
$$

From inspection of equations (24)-(27), it is possible to reduce the VDGA parasitic influences on the proposed circuits by taking the following conditions in the design: $R_{1}<<R_{z+}, R_{x}<<R_{n^{\prime}} C_{1}>>C_{z+}$ and $C_{2}>>\left(C_{x}+C_{n}\right)$.

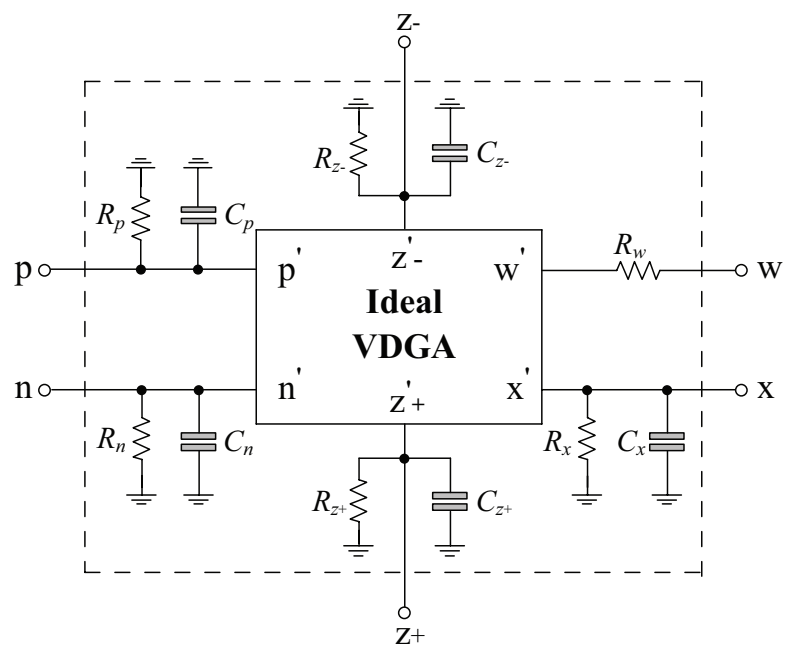

Figure 5: Practical VDGA model

\section{Simulation results and discussions}

The correct operation of the proposed dual-mode multifunction filter and QO topologies in Fig. 3 and 4 is assessed through PSPICE simulation results. For this purpose, the transistor models of the TSMC $0.25-\mu \mathrm{m}$ CMOS process parameters have been used. The CMOS VDGA in Fig. 2 is simulated under DC supply voltages of $\pm 1 \mathrm{~V}$. The values of transistor aspect ratios (W/L) are provided in Table 1.

Table 1: Values of transistor aspect ratios (W/L) of the VDGA circuit in Fig.2.

\begin{tabular}{|c|c|c|}
\hline \multicolumn{1}{c|}{ Transistor } & $W(\mu \mathrm{m})$ & $\mathrm{L}(\mu \mathrm{m})$ \\
\hline $\mathrm{M}_{1 \mathrm{k}}-\mathrm{M}_{2 \mathrm{k}}$ & 15 & 0.25 \\
\hline $\mathrm{M}_{3 \mathrm{k}}-\mathrm{M}_{4 \mathrm{k}}$ & 23 & 0.25 \\
\hline $\mathrm{M}_{5 \mathrm{k}}-\mathrm{M}_{7 \mathrm{k}}$ & 4.5 & 0.25 \\
\hline $\mathrm{M}_{8 \mathrm{k}}-\mathrm{M}_{9 \mathrm{k}}$ & 6 & 0.25 \\
\hline
\end{tabular}

6.1 Simulation results of the proposed dual-mode multifunction biquadratic filter

For the proposed dual-mode multifunction biquadratic filter in Fig.3, the active and passive components are taken as: $g_{m k} \cong 1 \mathrm{~mA} / \mathrm{V}\left(I_{B k}=100 \mu \mathrm{A}\right), R_{1}=R_{2}=1 \mathrm{k} \Omega$ and $C_{1}=C_{2}=100 \mathrm{pF}$ which result in $f_{0} \cong 1.59 \mathrm{MHz}$ and $Q$ $\cong 1$. The simulated and ideal frequency responses for the voltage and current gains are represented in Fig.6. In Fig.7, the input and output waveforms for the proposed BP filters at 1.59-MHz sinusoidal input signals are also shown. Total harmonic distortions (THDs) are less than $4 \%$ and $1.6 \%$ for the voltage-mode and currentmode BP filters, respectively. In addition to the simulation result, this filter has the total power consumption of about $1.49 \mathrm{~mW}$. Next, the large-signal behavior of the proposed filter is also evaluated by applying a sinusoidal input signal of $1.59 \mathrm{MHz}$. The BP output responses are found to demonstrate the THD variations of input signal amplitude as shown in Fig.8.

(a)

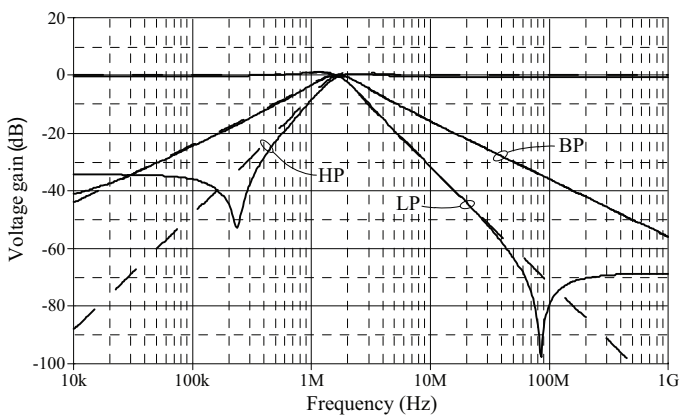

(b)

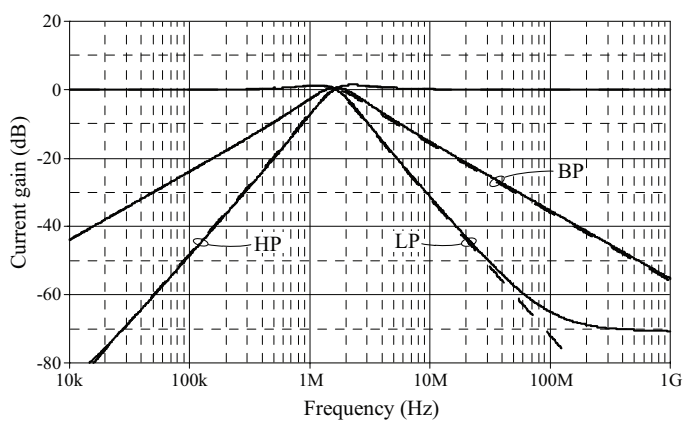

Figure 6: Simulated and ideal frequency responses of the proposed dual-mode multifunction filter in Fig.3 (solid line: simulated response, dashed line: ideal response). (a) voltage-mode (b) current-mode.

To test the adjustability of $Q$-factor without changing the $f_{o}$-value, the following circuit components are selected as: $g_{m k}=1 \mathrm{~mA} / \mathrm{V}, C_{1}=C_{2}=100 \mathrm{pF}$, with four different values of $R_{1}$ namely $0.5 \mathrm{k} \Omega, 1 \mathrm{k} \Omega, 2 \mathrm{k} \Omega$, and $10 \mathrm{k} \Omega$. The four BP voltage responses are illustrated in Fig.9, which accordingly shows the orthogonal variability of $Q$-factor. Furthermore, by keeping the product of $g_{m 1} R_{1}$ constant, and tuning the value of $g_{m 1} / R_{1}$ only, an independent tunability of $f_{o}$ can be obtained as shown in 
(a)

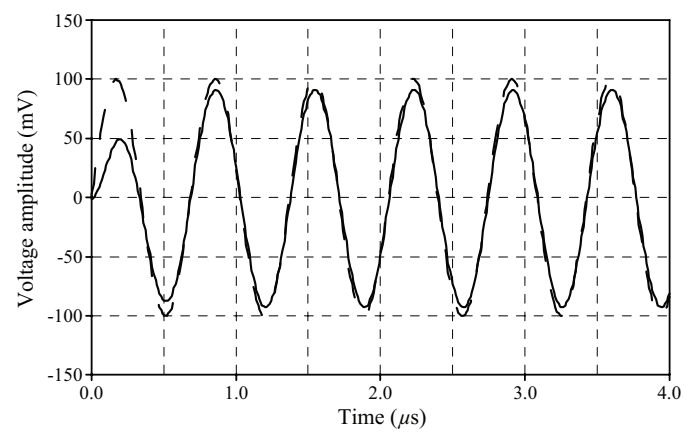

(b)

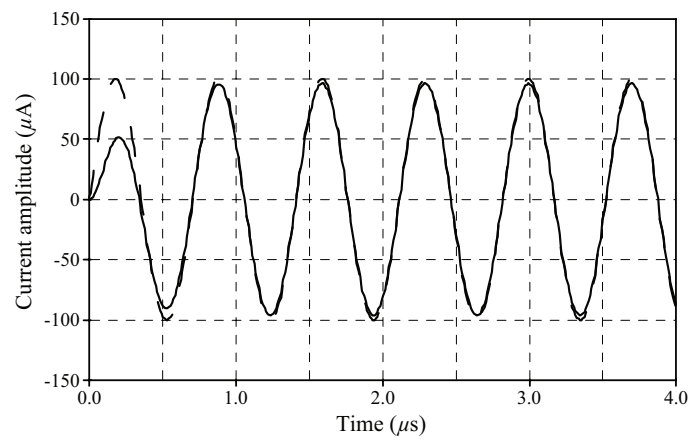

Figure 7: Input (dashed line) and output (solid line) waveforms of the BP filter for 1.59-MHz sinusoidal input signal. (a) voltage-mode (solid line: $v_{01}$, dashed line: $v_{i n}$ ), (b) current-mode (solid line: $i_{o 2^{\prime}}$ dashed line: $i_{i n}$ )

Fig.10. The component values for simulating the realized BP filter with different $f_{0}$ and their resulting characteristics are given in Table 2.

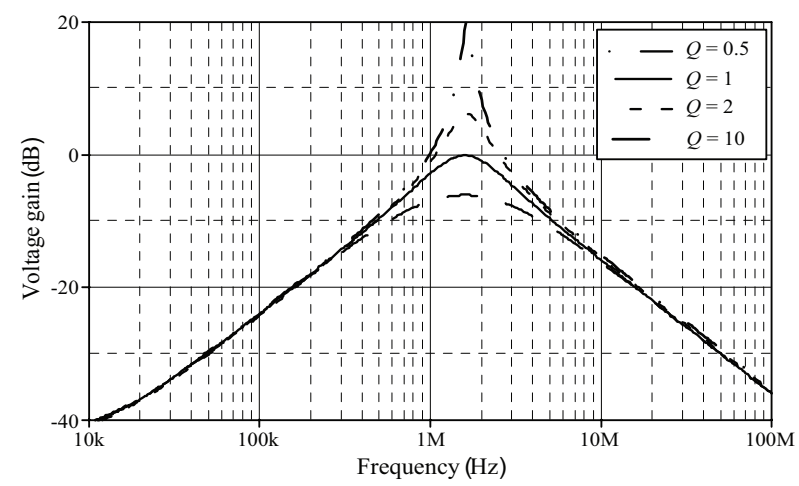

Figure 9: Gain-frequency characteristics with $Q=0.5$, 1,2 , and 10 of the proposed voltage-mode BP filter in Fig.3.
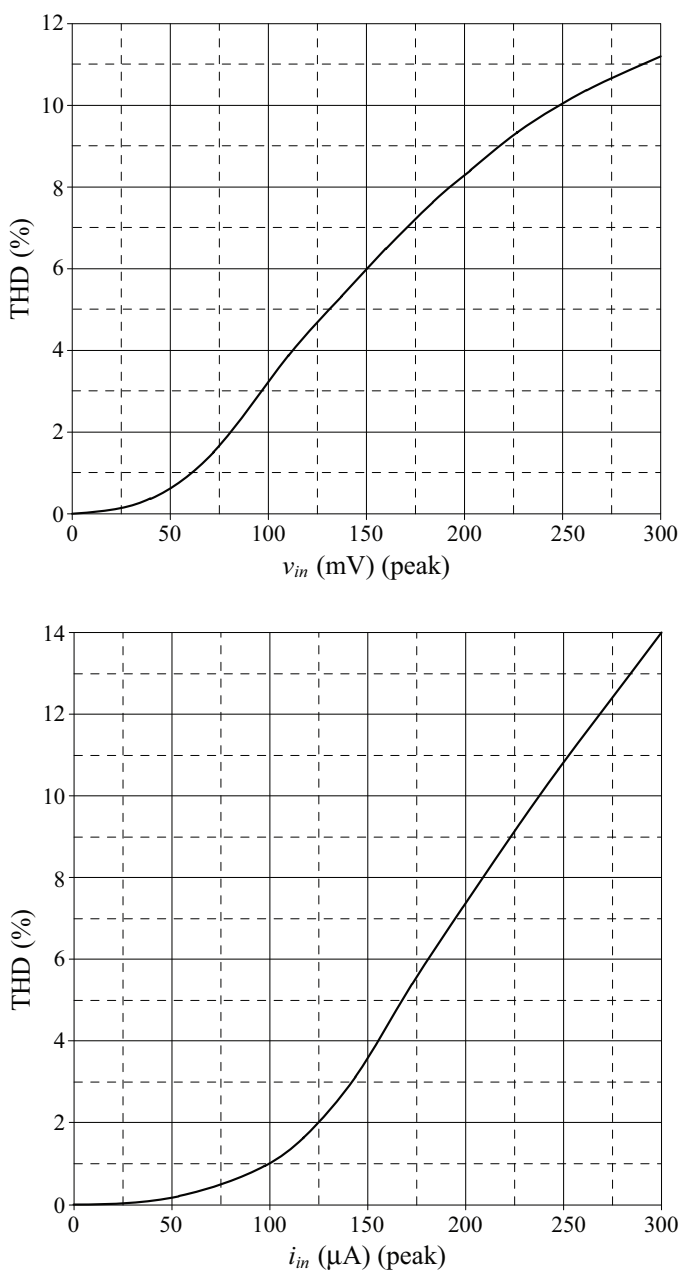

Figure 8: THD variations of the $\mathrm{BP}$ response versus input signal amplitude at $1.59 \mathrm{MHz}$. (a) voltage-mode (b) current-mode.

To evaluate the mismatch and process variation effects, Monte Carlo (MC) analysis has been performed for 100 iterations. MC simulation results showing deviations in filter responses for $5 \%$ changes in all passive elements $\left(R_{1}, R_{2}, C_{1}\right.$, and $\left.C_{2}\right)$ and transconductances $\left(g_{m k}\right)$ are illustrated in Fig.11(a) and 11(b), respectively. Temperature variation impacts on the filter responses are also studied for observed range $0^{\circ} \mathrm{C}$ to $100^{\circ} \mathrm{C}$. The simulation results of the gain-frequency characteristics with a variation in operating temperature are drawn in Fig. 12. From the graph, the value of $f_{o}$ varies from $1.69 \mathrm{MHz}$ at

Table 2: Component values for implementing the proposed BP filter in Fig.3 with independent adjustability of $f_{\circ}$.

\begin{tabular}{|c|c|c|c|c|c|c|c|}
\hline \multirow[b]{2}{*}{$g_{m k}(m A / V)$} & \multirow[b]{2}{*}{$I_{B k}(\mu A)$} & \multirow[b]{2}{*}{$\mathrm{R}_{1}(\mathrm{k} \Omega)$} & \multirow[b]{2}{*}{$g_{m k} R_{1}$} & \multirow[b]{2}{*}{$\mathrm{g}_{\mathrm{mk}} / \mathrm{R}_{1}$} & \multicolumn{2}{|c|}{$\mathrm{f}_{\mathrm{o}}(\mathrm{MHz})$} & \multirow[b]{2}{*}{ Q } \\
\hline & & & & & Simulated & Theory & \\
\hline 0.63 & 40 & 1.6 & 1 & $0.40 \mathrm{E}-06$ & 1.01 & 0.98 & 1 \\
\hline 1.00 & 100 & 1.0 & 1 & $1.00 \mathrm{E}-06$ & 1.59 & 1.54 & 1 \\
\hline 1.35 & 180 & 0.74 & 1 & 1.82E-06 & 2.15 & 2.05 & 1 \\
\hline
\end{tabular}




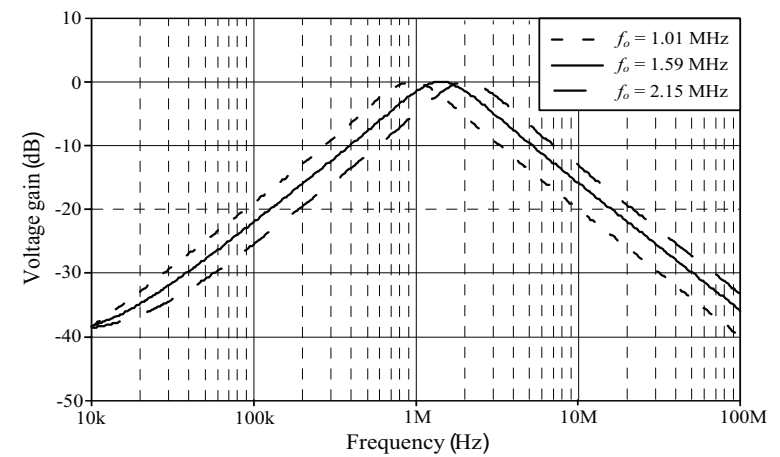

Figure 10: Gain-frequency characteristics with independent adjustability of $f_{o}$ of the proposed voltagemode BP filter in Fig.3.

$0^{\circ} \mathrm{C}$ to $1.35 \mathrm{MHz}$ at $100^{\circ} \mathrm{C}$ with a maximum deviation of $17 \%$. It may also be observed that the $f_{o}$-value shifts to the lower frequencies with an increase in temperature. This is due to the fact that the transconductance decreases with increases in temperature due to decrease in mobility. This shifting in $f_{o}$ can easily be compensated through bias current variation, or the PTAT (Proportional to Absolute Temperature) current reference can be used as bias current sources to compensate for the temperature behavior of the proposed circuits.

(a)

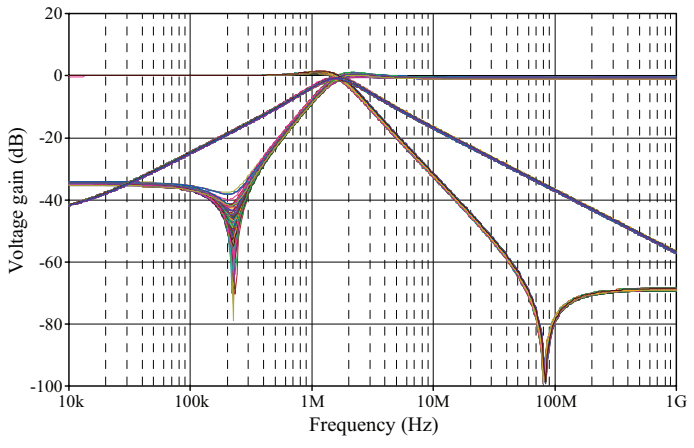

(b)

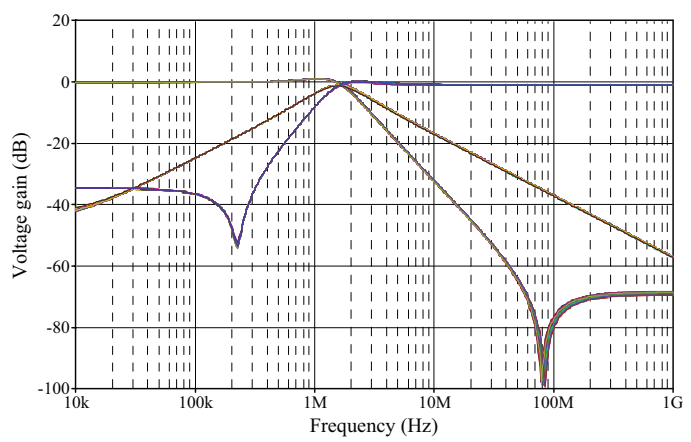

Figure 11: Monte Carlo analyses with 100 iterations, showing variations in LP, BP and HP filter responses, due to $5 \%$ changes in (a) all resistors and capacitors (b) all transconductances.

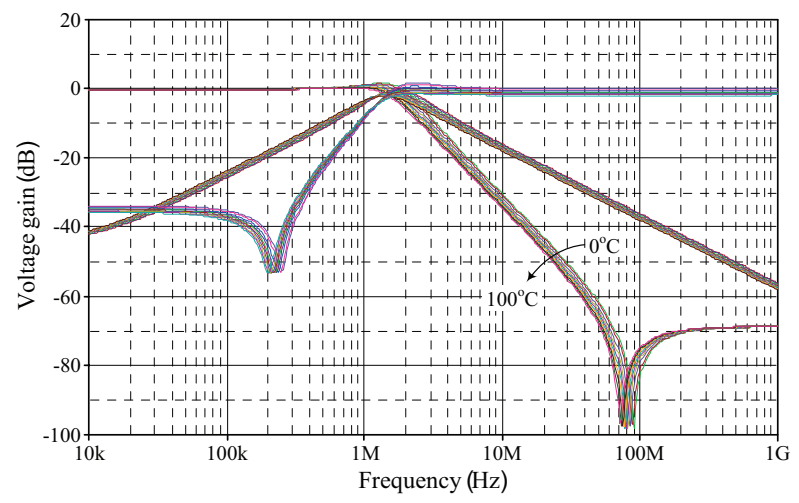

Figure 12: Gain-frequency characteristics with a variation in temperature from $0^{\circ} \mathrm{C}$ to $100^{\circ} \mathrm{C}$.

\subsection{Simulation results of the proposed dual-mode quadrature sinusoidal oscillator}

With the same above designed values, the proposed dual-mode QO circuit of Fig.4 has been simulated for a frequency of oscillation of $f_{\text {osc }}=1.59 \mathrm{MHz}$. Simulation results of the voltage and current quadrature output responses are shown in Fig.13 and 14, respectively. Fig.13(a) indicates the two quadrature voltage outputs difference in phase by $88^{\circ}$, while Fig.14(a) shows $91^{\circ}$ phase-shifted quadrature current outputs. The observed THD for both voltage and current outputs are around $3.76 \%$ and $3.73 \%$, respectively. The Lissajous patterns for the two voltage and two current outputs are further depicted through Fig.15(a) and 15(b), respectively. It is observed that the resultants produce circles around the origin with no tilt in axis illustrating the quadrature property of the proposed oscillator circuit.

\section{Conclusions}

The paper proposes compact circuit configurations for realizing dual-mode (i.e. both voltage-mode and current- mode) multifunction biquadratic filter and quadrature sinusoidal oscillator. Each of the proposed circuit configurations requires a single VDGA, two grounded capacitors, and two resistors (one of them is grounded). The proposed filter can realize simultaneously the three standard biquadratic filtering functions, i.e. $\mathrm{LP}, \mathrm{BP}$, and $\mathrm{HP}$ ones, with both voltage and current output responses. It has also capable of independent control of $\omega_{o}$ and $Q$-factor. Another notable advantage of the proposed circuit is that it can also be used as a sinusoidal quadrature oscillator to provide two quadrature voltage outputs and two quadrature current outputs simultaneously. The oscillation condition and the oscillation frequency of the proposed dual-mode QO are orthogonally controllable by separate bias currents. 
The effect of non-idealities influences of the VDGA on the circuit functionality has been studied, and simulation results using PSPICE with TSMC $0.25-\mu \mathrm{m}$ CMOS technology have also been included to validate the functionality of the proposed circuits in both frequency filter and oscillator mode.

(a)

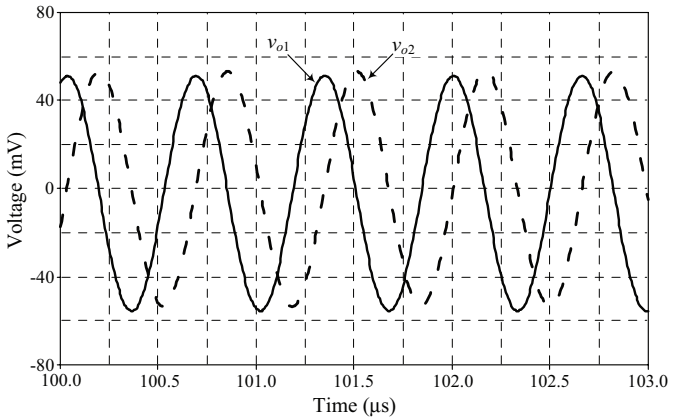

(b)

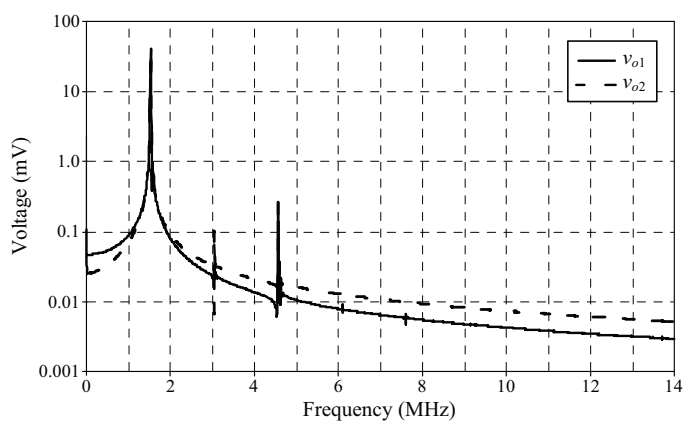

Figure 13: Simulated voltage output responses.

(a) time-domain responses (b) frequency spectrum.

(a)

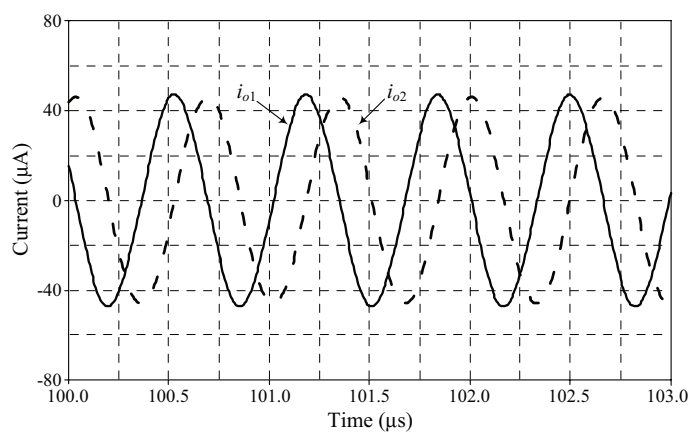

(b)

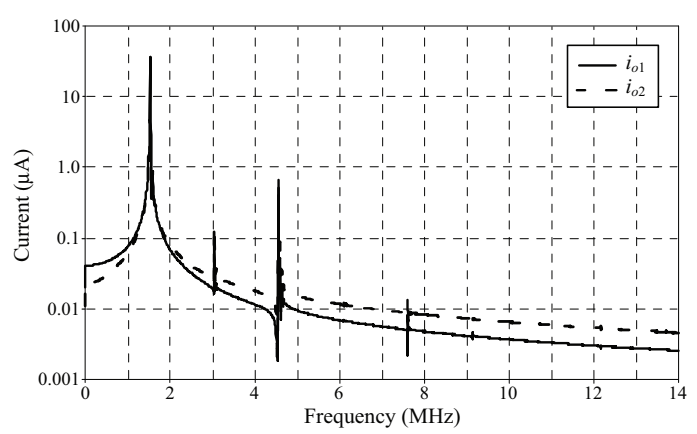

Figure 14: Simulated current output responses.

(a) time-domain responses (b) frequency spectrum. (a)

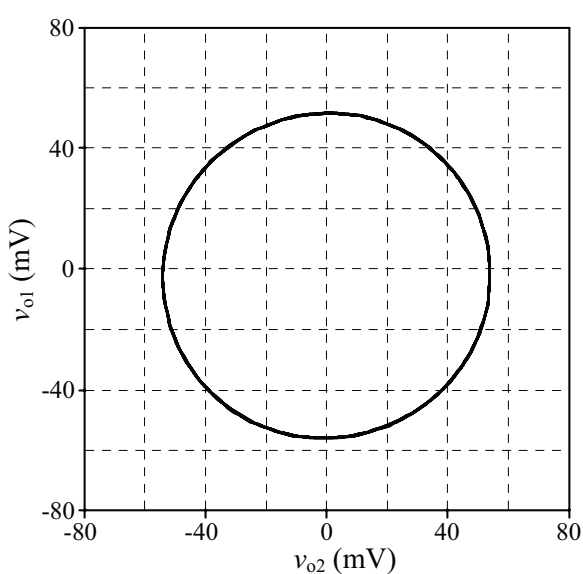

(b)

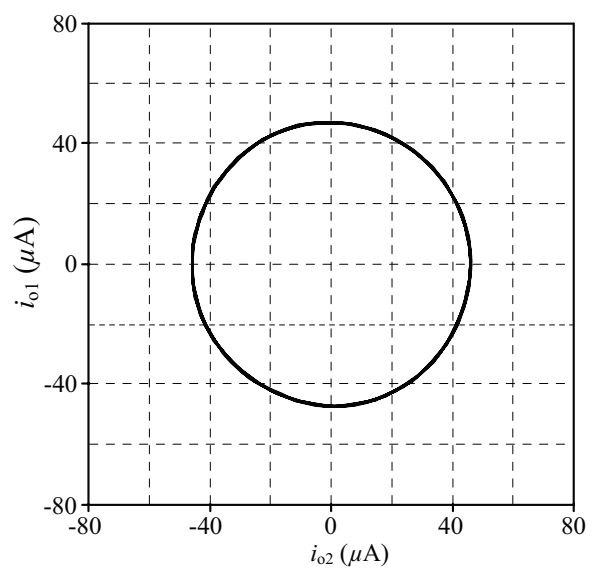

Figure 15: Lissajous patterns illustrating the quadrature property. (a) voltage-mode (b) current-mode.

\section{Acknowledgments}

This research project was supported by Rajamangala University of Technology Isan, Contract No. ENG28/63. This work was also partly supported by King Mongkut's Institute of Technology Ladkrabang Research Fund [grant number KREF046213].

\section{Conflict of Interest}

The authors confirm that this article content has no conflict of interest.

\section{References}

1. O. Cicekoglu, N. Tarim, H. Kuntman, "Wide dynamic range high output impedance current-mode multifunction filters with dual-output current conveyors", Int. J. Electron. Commun. (AEU), vol.56, no.1, pp.55-60, 2002, https://doi.org/10.1078/1434-8411-54100073. 
2. M. A. Ibrahim, S. Minaei, H. Kuntman, "A $22.5 \mathrm{MHz}$ current-mode KHN biquad using differential voltage current conveyor and grounded passive element", Int. J. Electron. Commun. (AEU), vol.59, pp.311-318, 2005,

https://dx.doi.org/10.1016/j.aeue.2004.11.027.

3. J. W. Horng, "Voltage-mode multifunction biquadratic filter employing single DVCC", Int. J. Electron., vol.99, no.2, pp.153-162, 2012, https://doi.org/10.1080/00207217.2011.623268 .

4. J. W. Horng, W. Y. Chiu, and H. Y. Wei, "Voltagemode highpass, bandpass and lowpass filters using two DDCCs", Int. J. Electron.., vol.91, no.8, pp.461-464, 2004, https://doi.org/10.1080/00207210412331294603

5. J.W. Horng, J. R. Lay, C. W. Chang, M. H. Lee, "High input impedance voltage-mode multifunction filters using plus-type CCIls", Electron. Lett., vol. 33, no. 6, pp. 472-473, 1997, https://doi.org/10.1049/el:19970297.

6. C. M. Chang, M. J. Lee, "Voltage-mode multifunction filter with single input and three outputs using two compound current conveyors", IEEE Trans. Circuits Syst.-I: Fundamental Theory and Applications, vol. 46, no. 11, pp. 1364-1365, 1999, https://doi.org/10.1109/81.802827.

7. F. Yucel, E. Yuce, "A new CCII based voltage-mode multifunctional filter with reduced number of active and passive elements", J. Circuits Syst. Comp. vol.24, no. 4, 1550047 (11 pages), 2015, https://doi.org/10.1142/s0218126615500474.

8. S. Ozcan, O. Cicekoglu, and H. Kuntman, "Multiinput single-output filter with reduced number of passive elements employing single current conveyor", Comp. Electri. Eng., vol.29, pp.45-53, 2003, https://doi.org/10.1016/s0045-7906(01)00024-6.

9. H. Y. Wang, C. T. Lee, "Versatile insensitive currentmode universal biquad implementation using current conveyors", IEEE Trans. Circuits Syst.-II: Analog and Digital Signal Processing, vol.48, no.4, pp.409-413, 2001,

https://doi.org/10.1109/82.933806.

10. S. Maheshwari, "High performance voltage-mode multifunction filter with minimum component count", WSEAS Trans. Electron., vol.5, pp.244-249, 2008.

11. E. Yuce, "Voltage-mode multifunction filters employing a single DVCC and grounded capacitors", IEEE Trans. Instrum. Meas., vol. 58, no. 7, pp.22162221, 2009, https://doi.org/10.1109/tim.2009.2013671.

12. W. Tangsrirat, and O. Channumsin, "High-input impedance voltage-mode multifunction filter using a single DDCCTA and grounded passive elements", Radioengineering, vol.20, no.4, pp.905910, 2011.
13. M. Minarcik, and K. Vrba, "Single-input six-output voltage-mode filter using universal voltage conveyors", IEICE Trans. Fundamentals., vol.E91-A, no.8, pp.2035-2037, 2008, https://doi.org/10.1093/ietfec/e91-a.8.2035.

14. H. Alpaslan, and E. Yuce, "Current-mode biquadratic universal filter design with two terminal unity gain cells", Radioengineering, vol.21, no.1, pp.304-311, 2012.

15. S. S. Gupta, and R. Senani, "New voltage-mode/ current- mode universal biquad filter using unitygain cells", Int. J. Electron., vol.93, no.11, pp.769775, 2006, https://doi.org/10.1080/00207210600711622.

16. H. P. Chen, and P. L. Chu, "Versatile universal electronically tunable current-mode filter using CCCIIs", IEICE Electronics Express, vol.6, no.2, pp.122128,2009 , https://doi.org/10.1587/elex.6.122.

17. E. Yuce, A. Kircay, and S. Tokat, "Universal resistorless current-mode filters employing CCCIIs", Int. J. Circ. Theor. Appl., vol.36, no.5-6, pp.739-755, 2008, https://doi.org/10.1002/cta.455.

18. W. Chunhua, A. U. Keskin, L. Yang, Z. Qiujing, and D. Sichun, "Minimum configuration insensitive multifunctional current-mode biquad using current conveyors and all-grounded passive components", Radioengineering, vol.19, no.1, pp.178-184, 2010.

19. O. Channumsin, and W. Tangsrirat, "Dual-mode multifunction filter using VDGAs", Proc. $15^{\text {th }}$ Int. Conf. Electri./Electron. Comput. Telecommun. Informa. Tech. (ECTI-CON 2018), Chiang Rai, Thailand, July 18-21, pp. 90-93, 2018.

20. J. Satansup, T. Pukkalanun, and W. Tangsrirat, “Electronically tunable single-input five-output voltage-mode universal filter using VDTAs and grounded passive elements," Circuits Syst. Signal Process, vol. 32, no. 3, pp. 945-957, 2013, https://doi.org/10.1007/s00034-012-9492-0.

21. J. Satansup and W. Tangsrirat, "Compact VDTA-based current-mode electronically tunable universal filters using grounded capacitors,"Microelectron. J., vol. 45, no. 6, pp. 613-618, 2014, https://doi.org/10.1016/j.mejo.2014.04.008.

22. N. Singhal, R. Pandey, and N. Pandey, "Dual mode biquadratic filter using single VDTA," Int. J. Electri. Electron. Eng., vol. 6, pp.134-139, 2014.

23. R. Pandey, N. Pandey, and N. Singhal, "Single VDTA based dual mode single input multioutput biquad filter", J. Engineering, vol. 2016, Article ID 1674343, 10 pages, 2016, http://dx.doi.org/10.1155/2016/1674343. 
24. J. W. Horng, "Quadrature oscillators using operational amplifiers", Active and Passive Electron. Comp., vol. 2011, Article ID 320367, 4 pages, 2011, https://doi.org/10.1155/2011/320367.

25 N. Minhaj, "Current conveyor-based voltagemode two-phase and four-phase quadrature", Int. J. Electron., vol.94, no.7, pp.663-669, 2007, https://doi.org/10.1080/0020721070140587.

26. J. W. Horong, C. L. hou, C. M. Chang, W. Y. Chung, H. W. Tang, and Y. H. Wen, "Quadrature oscillators using CClls", Int. J. Electron., vol.92, no.1, pp.21-31, 2005,

https://doi.org/10.1080/00207210412331332899

27. M. Kumngern, and K. Dejhan, “DDCC-based quadrature oscillator with grounded capacitors and resistors", Active and Passive Electron. Comp., vol.2009, Article ID 987304, 4 pages, 2009, https://doi.org/10.1155/2009/987304.

28. S.I. Liu, and Y.H. Liao, "Current mode quadrature sinusoidal oscillator using single FTFN", Int. J. Electron., vol.81, no.2, pp.171-175, 1996, https://doi.org/10.1080/002072196136832.

29. D. R. Bhaskar, R. Senani, "New FTFN-based grounded-capacitor SRCO with explicit currentmode output and reduced number of resistors", Int. J. Electron. Commun. (AEU), vol.59, no.1, pp.4851, 2005 , https://doi.org/10.1016/j.aeue.2004.11.029.

30. U. Cam, A. Toker, O. Cicekoglu, H. Kuntman, "Current-mode high output impedance sinusoidal oscillator configuration employing single FTFN", Analog Integr. Circ. Sig. Process., vol.24, no.3, pp.231-238, 2000, https://doi.org/10.1023/A:1008365726144.

31. A. M. Soliman, “Current feedback operational amplifier based oscillators", Analog Integr. Circ. Sig. Process., vol.23, no.1, pp.45-55, 2000, https://doi.org/10.1023/A:1008391606459.

32. W. Tangsrirat, W. Surakampontorn, "Single-resistance-controlled quadrature oscillator and universal biquad filter using CFOAs", Int. J. Electron. Commun. (AEU), vol.63, no.12, pp.1080-1086, 2009, https://doi.org/10.1016/j.aeue.2008.08.006.

33. A. Lahiri, W. Jaikla, M. Siripruchyanun, "First CFOAbased explicit-current-output quadrature sinusoidal oscillators using grounded capacitors", Int. J. Electron., vol.100, no.2, pp.259-273, 2013, https://doi.org/10.1080/00207217.2012.692632.

34. A.U. Keskin, "Voltage-mode high-Q band-pass filters and oscillators employing single CDBA and minimum number of components", Int. J. Electron., vol.92, no.8, pp.479-487, 2005, https://doi.org/10.1080/00207210500168626.

35. W. Tangsrirat, D. Prasertsom, T. Piyatat, W. Surakampontorn, "Single-resistance-controlled quadrature oscillator using current differencing buffered amplifiers", Int. J. Electron., vol.95, no.11, pp. 1119-1126, 2008,

https://doi.org/10.1080/00207210802387676.

36. W. Tangsrirat, W. Tanjaroen, "Current-mode quadrature oscillator with independent control of oscillation frequency and condition using CDTAs", Indian J. Pure \& Appl. Phys., vol.48, no.5, pp.363366, 2010.

37. J. Jin, C. Wang, "Single CDTA-based current-mode quadrature oscillator", Int. J. Electron. Commun. (AEU), vol.66, no.11, pp.933-936, 2012, https://doi.org/10.1016/j.aeue.2012.03.018.

38. J. Jin, C. Wang, "CDTA-based electronically tunable current-mode quadrature oscillator", Int. J. Electron., vol.101, no.8, pp. 1086-1095, 2014, https://doi.org/10.1080/00207217.2013.805394.

39. K. Banerjee, D. Singh, S. K. Paul, "Single VDTA based resistorless quadrature oscillator", Analog Integr. Circ. Sig. Process., vol.100, no.2, pp.495-500, 2019, https://doi.org/10.1007/s10470-019-01480-4.

40. A. Yesil, F. Kacar, and K. Gurkan, "Design and experimental evaluation of quadrature oscillator employing single FB-VDBA", J. Electri. Eng., vol.67, no.2, pp.136-142, 2016, https://doi.org/10.1515/jee-2016-0019.

41. J. W. Horng, C. L. Hou, C. M. Chang, H. P. Chou, C. T. Lin, and Y. H. Wen, "Quadrature oscillators with grounded capacitors and resistors using FDCClls", ETRI J., vol. 28 no.4, pp.486-494, 2006, https://doi.org/10.4218/etrij.06.0105.0181.

42. S. Maheshwari, I. A. Khan, "Novel single resistor controlled quadrature oscillator using two CDBAs", J. Active Passive Devices, vol.2, pp.137-142, 2007.

43. A. Lahiri, "Novel voltage/current-mode quadrature oscillator using current differencing transconductance amplifier", Analog Integr. Circ. Sig. Process., vol.61, no.2, pp.199-203, 2009, https://doi.org/10.1007/s10470-009-9291-0.

44. S. Maheshwari, "Quadrature oscillator using grounded components with current and voltage outputs", IET Circuits Devices Syst., vol.3, no.4, pp.153-160, 2009, https://doi.org/10.1049/iet-cds.2009.0072.

45. A. Lahiri, "Explicit-current-output quadrature oscillator using second-generation current conveyor transconductance amplifier", Radioengineering, vol.18, no.4, pp.522-526, 2009.

46. W. Tangsrirat, "Dual-mode sinusoidal quadrature oscillator with single CCTA and grounded capacitors", Informacije MIDEM, vol.46, no.3, pp.130-135, 2016.

47. M. Srivastaya, D. Prasad, "VDCC based dual-mode sinusoidal quadrature oscillator with outputs at appropriate impedance", Theoretical and Applied Electrical Eng., vol.14, no.2, pp.168-177, 2016, https://doi.org/10.15598/aeee.v14i2.1611. 
48. W. Tangsrirat, "Compact quadrature oscillator with voltage and current outputs using only single VDTA and grounded capacitors", Indian J. Pure \& Appl. Phys., vol.55, no.4, pp.254-260, 2017.

49. A. Yesil, F. Kacar, "Current and voltage mode quadrature oscillator based on voltage differencing buffered amplifier", Electrica, vol.18, no.1, pp.6-12, 2018, https://doi.org/10.5152/iujeee.2018.1802.

50. J. Satansup, W. Tangsrirat, "CMOS realization of voltage differencing gain amplifier (VDGA) and its application to biquad filter", Indian J. Eng. Mater. Sci., vol.20, no.6, pp.457-464, 2013.

51. Z. G. Cam Taskiran, H. Sedef and F. Anday, "Voltage differencing gain amplifier-based Nth-order lowpass voltage-mode filter", J. Circuit. Syst. Comp., vol.27, no.6, 2018, https://doi.org/10.1142/S0218126618500895.

52. O. Channumsin and W. Tangsrirat, "Compact electronically tunable quadrature oscillator using single voltage differencing gain amplifier (VDGA) and all grounded passive elements", Turk. J. Elec. Eng. \& Comp. Sci., vol.25, pp.2686-2695, 2017, https://doi.org/10.3906/elk-1607-1.

53. O. Channumsin, W. Tangsrirat, "Voltage differencing gain amplifier-based sinusoidal quadrature oscillator using only two grounded capacitors", Recent Advances in Electrical \& Electronic Engineering, vol.12, no.5 , pp.439-444, 2019, https://doi.org/10.2174/2352096512666181219121941

54. W. Tangsrirat, O. Channumsin, and J. Pimpol, "Electronically adjustable capacitance multiplier circuit with a single voltage differencing gain amplifier (VDGA)", Informacije MIDEM, vol.49, no.4, pp.211-217, 2019,

https://doi.org/10.33180/infmidem2019.403.

55. A. F. Arbel, L. Goldminz, "Output stage for currentmode feedback amplifiers, theory and applications", Analog Integr. Circ. Sig. Process., vol.2, no.3, pp.243-255, 1992, https://doi.org/10.1007/bf00276637.

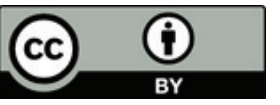

Copyright (c) 2020 by the Authors. This is an open access article distributed under the Creative Commons Attribution (CC BY) License (https://creativecommons.org/licenses/by/4.0/), which permits unrestricted use, distribution, and reproduction in any medium, provided the original work is properly cited. 